\title{
EFEITO DE DIFERENTES SUBSTRATOS E ÉPOCAS DE COLETA NO ENRAIZAMENTO DE ESTACAS HERBÁCEAS DE GOIABEIRA, cvs. PALUMA E SÉCULO XXI ${ }^{1}$
}

\author{
CORINA ZIETEMANN² \& SÉRGIO RUFFO ROBERTO ${ }^{3}$
}

RESUMO - Este trabalho objetivou avaliar o enraizamento de estacas herbáceas das goiabeiras 'Paluma' e 'Século XXI' em diferentes substratos, coletadas na primavera e no verão. As estacas foram obtidas de ramos jovens não-lignificados de árvores de quatro anos, com um par de folhas no nó superior e $10 \mathrm{~cm}$ de comprimento. Para cada época testada, as estacas foram tratadas por imersão rápida, com cinco doses de AIB $(0 ; 500 ; 1.000 ; 1.500$ e $2.000 \mathrm{mg} / \mathrm{L})$ e dispostas em bandejas plásticas perfuradas com dois substratos (casca de arroz carbonizada e vermiculita) em câmara de nebulização. Após 70 dias da estaquia, foram avaliadas as seguintes variáveis: porcentagem de enraizamento; massas seca e fresca das raízes; número de raízes por estaca; comprimento das raízes; sobrevivência; retenção foliar e porcentagem de estacas com calo. Concluiu-se que houve maior enraizamento das estacas coletadas no verão e que as doses de 1.500 e $2.000 \mathrm{mg} / \mathrm{L}$ de AIB são as mais adequadas para promover as melhores características de enraizamento das estacas para as cvs. Paluma e Século XXI, respectivamente. Os dois substratos utilizados são indicados para a estaquia das goiabeiras estudadas.

Termos para indexação: AIB, câmara de nebulização, Psidium guajava L.

\section{EFFECT OF DIFFERENT SUBSTRATES AND COLLECTION SEASONS ON THE HERBACEOUS CUTTINGS ROOTING OF GUAVA, cvs. PALUMA AND SÉCULO XXI}

\begin{abstract}
The objective of this research was to evaluate the influence of different substrates and collection season on the herbaceous cutting rooting of 'Paluma' and 'Século XXI' guava plants (Psidium guajava L.). The herbaceous cuttings were obtained on spring and summer seasons, consisted of $10 \mathrm{~cm}$ of length, two nodes and a pair of leaves in the superior node, and treated with five doses of IBA $(0,500,1,500$ and $2,000 \mathrm{mg} / \mathrm{L})$ for each season studied, and disposed into plastic boxes containing hull rice coal and vermiculita as substrates. After 70 days, the rooting percentage, roots length, number of roots, fresh and dry matter of roots, survival percentage, foliar retention and percentage of cuttings with callus were evaluated. The results showed that the better rooting percentage occurred in cuttings collected in summer; the 1,500 and 2,000 mg/L of IBA were the most appropriate to provide the best rooting characteristics of 'Paluma' and 'Século XXI' herbaceous cuttings, respectively. Both substrates are indicated for the guava cultivars herbaceous cuttings rooting studied.
\end{abstract}

Index terms: IBA, mist chamber, Psidium guajava L.

\section{INTRODUÇÃO}

A estaquia de ramos herbáceos em goiabeira é um processo que vem sendo pesquisado há anos (Kersten \& Ibañes, 1993; Bacarin et al., 1994; Tavares et al., 1995) e, atualmente, está sendo mais utilizado no Brasil para a produção comercial de mudas. A formação de estacas por processos vegetativos de propagação origina mudas uniformes e que mantêm as mesmas características genotípicas das plantas das quais foram retiradas. São mantidas a qualidade dos frutos, a produtividade e a precocidade de produção, que são fatores importantes no processo de produção comercial de mudas (Rom \& Carlson, 1987; Meletti et al., 2000; Hartmann \& Kester, 2002).

Dentre os tipos de estacas de goiabeira, a herbácea é a que tem sido produzida com mais sucesso em grande escala, uma vez que a muda é formada com muita rapidez, exige menos tempo de trabalho e origina mudas com qualidade e com baixo custo. As estacas herbáceas são aquelas retiradas de ramos do último fluxo vegetativo, de coloração verde e que ainda não sofreram processo de lignificação (Manica et al., 2000).

Para potencializar o processo de enraizamento, é usual a aplicação de reguladores de crescimento, como o ácido indolbutírico (AIB). O efeito benéfico do AIB sobre a propagação de estacas tem sido observado em diversas culturas e para diversas finalidades, principalmente com relação ao aumento da porcentagem de enraizamento e à quantidade de raízes formadas (Mayer et al., 2001; Andrade \& Martins, 2003; Oliveira et al., 2003; Frangi \& Nicola, 2005; Krisantini et al., 2006).

Estudos têm demonstrado o sucesso na estaquia da goiabeira (Pereira et al., 1991; Kersten \& Ibañes, 1993; Bacarin et al., 1994; Tavares et al., 1995). No entanto, foi verificado que podem existir diferenças de resposta entre diferentes cultivares

\footnotetext{
${ }^{1}$ (Trabalho 086-2006). Recebido: 30-05-2006. Aceito para publicação: 04-12-2006. (Parte da dissertação de mestrado na área de Agronomia do primeiro autor, Universidade Estadual de Londrina).

2 Bióloga, M. Sc., Universidade Estadual de Londrina, CP 6001, 86051-990, Londrina-PR. corinaz@ pop.com.br

${ }^{3}$ Eng. Agr., Dr. Sc., Professor Adjunto, Departamento de Agronomia/Fitotecnia, Universidade Estadual de Londrina, Bolsista do CNPq, CP 6001, 86051990, Londrina-PR. sroberto@uel.br
} 
(Tavares et al., 1995; Costa Jr. et al., 2003) e que a época em que são retiradas as estacas, também pode influenciar no seu enraizamento (Pereira et al., 1991; Tavares et al., 1995).

A cultivar Paluma é amplamente difundida no País pelas ótimas características produtivas, pela qualidade dos frutos e pela tolerância a doenças (Pereira, 1984). O seu plantio é muito bem distribuído, inclusive no norte do Paraná, sendo a cultivar mais plantada atualmente no Brasil. A 'Século XXI' é uma nova cultivar de polpa vermelha, lançada no mercado, e promete ser uma excelente opção para os produtores, pela sua qualidade e produtividade (Pereira et al., 2003). Entretanto, poucas são as informações a respeito da época adequada para a coleta de estacas assim como os substratos indicados para a estaquia e a produção comercial de mudas no norte do Paraná, o que motivou esta pesquisa.

Desse modo este trabalho teve como objetivo estudar o enraizamento de estacas herbáceas das cultivares Paluma e Século XXI em dois substratos coletadas em duas épocas do ano, no norte do Paraná.

\section{MATERIAL E MÉTODOS}

O experimento foi conduzido entre os meses de novembro de 2004 e outubro de 2005, no setor de propagação de mudas frutíferas do Departamento de Agronomia da Universidade Estadual de Londrina, Paraná (latitude $23^{\circ} 27^{\prime} \mathrm{S}$, longitude $51^{\circ} 57^{\prime} \mathrm{W}$ e altitude de $585 \mathrm{~m}$ ), cujo clima é classificado como subtropical úmido (CWa), segundo a classificação de Köeppen, caracterizado por verão quente e inverno fresco, com chuvas bem distribuídas e geadas ocasionais de junho a agosto.

Foram utilizadas estacas herbáceas obtidas de ramos provenientes das cultivares de goiabeira Paluma e Século XXI (Psidium guajava L.), pertencentes à Fazenda Escola da UEL. Para a obtenção das estacas, as plantas-matrizes de aproximadamente quatro anos foram podadas no fim de agosto de 2004. Em novembro (70 dias após a poda, na primavera) e em fevereiro de 2005 (120 dias após a poda, no verão), as estacas foram obtidas da porção mediana de ramos jovens nãolignificados e preparadas de modo a conterem dois nós com um par de folhas no nó superior, tendo, em média, $10 \mathrm{~cm} \mathrm{de}$ comprimento (Bacarin et al., 1994 e Pereira et al., 1991).

O preparo da solução de AIB foi realizado em solução hidroalcoólica (50\% v/v) (Bacarin et al., 1994). O tratamento com o regulador de crescimento foi realizado pela imersão rápida da região basal das estacas por 5 segundos, em soluções com as seguintes doses: 0; 500; 1.000; 1.500 e 2.000 mg/L. Após o tratamento, as estacas foram imediatamente colocadas para enraizamento, em caixas plásticas perfuradas (dimensões de $44 \mathrm{x}$ $30 \times 7 \mathrm{~cm}$ ) contendo dois tipos de substratos: casca de arroz carbonizada (CAC) e vermiculita de granulação média (VGM). O substrato à base de casca de arroz carbonizada foi preparado conforme Kämpf et al. (2000). As caixas plásticas foram mantidas em bancadas suspensas a $80 \mathrm{~cm}$ do solo.

Os experimentos foram dispostos em câmara de nebulização intermitente controlado por temporizador e válvula solenóide (Gomes et al., 2000). Essa válvula foi programada para nebulizar as estacas durante cinco segundos, a cada intervalo de dois minutos. O bico nebulizador empregado (modelo Mist DanSprinklers, Israel) apresenta vazão de 35 L/hora. A câmara de nebulização encontrava-se inserida em uma estufa agrícola com cobertura de filme polietileno transparente e sombrite de $30 \%$. Para o controle fitossanitário, as estacas foram pulverizadas semanalmente com fungicida sistêmico (benomyl 1,0\%).

Foi adotado o delineamento inteiramente casualizado, em esquema fatorial $2 \times 2 \times 5$ (duas épocas de coleta das estacas, dois tipos de substrato e cinco doses de AIB), em um total de 20 tratamentos, com quatro repetições, sendo cada parcela composta por 10 estacas. Setenta dias decorridos a partir da instalação de cada um dos experimentos, foram avaliados: enraizamento das estacas (\% que emitiram pelo menos uma raiz); massas seca e fresca das raízes por estaca $(\mathrm{g})$; número de raízes por estaca (consideradas apenas aquelas que se originaram diretamente da estaca); comprimento das raízes $(\mathrm{cm})$; sobrevivência (\% de estacas vivas); retenção foliar (porcentagem de estacas que não perderam as folhas) e porcentagem de estacas com calo, porém não-enraizadas. A massa seca das raízes foi obtida através de sua secagem em estufa à temperatura de $78^{\circ} \mathrm{C}$, por 48h (Cyrillo et al., 1999).

A partir desses dados, foi analisado para cada uma das cultivares o efeito dos fatores (épocas de coleta de estacas, substratos e doses de AIB) para cada variável, pela análise de variância, sendo que a separação das médias foi realizada pelo teste de Tukey, a 5\% de probabilidade, no aplicativo Sisvar 4.6 (Ferreira, 2000). Quando necessário, efetuou-se a transformação de dados segundo a equação arco-seno $\sqrt{x / 100}$ para os dados em porcentagem e $\sqrt{x}$ para os valores quantitativos.

\section{RESULTADOS}

\section{'Paluma'}

Houve interação significativa entre os fatores época do ano e doses de AIB para a cultivar Paluma, para as variáveis massas seca e fresca de raízes (g), raízes por estaca, comprimento de raízes $(\mathrm{cm})$ e porcentagem de estacas com calo (Tabelas 1 e 2).

TABELA 1 - Interação entre épocas do ano e doses de AIB para massa seca e fresca das raízes da goiabeira 'Paluma'. Londrina- PR, 2005.

\begin{tabular}{lcccc}
\hline \multirow{2}{*}{$\begin{array}{l}\text { Doses de AIB } \\
(\mathrm{mg} / \mathrm{L})\end{array}$} & \multicolumn{2}{c}{ Massa seca $(\mathrm{g})$} & \multicolumn{2}{c}{ Massa fresca $(\mathrm{g})$} \\
\cline { 2 - 5 } & Primavera & Verão & Primavera & Verão \\
\hline 0 & $0,13 \mathrm{Aa}$ & $0,07 \mathrm{Ac}$ & $0,96 \mathrm{Aa}$ & $0,21 \mathrm{Ac}$ \\
500 & $0,15 \mathrm{Aa}$ & $0,19 \mathrm{Ab}$ & $0,96 \mathrm{Aa}$ & $1,65 \mathrm{Ab}$ \\
1.000 & $0,16 \mathrm{Ba}$ & $0,28 \mathrm{Ab}$ & $1,01 \mathrm{Ba}$ & $1,97 \mathrm{Ab}$ \\
1.500 & $0,16 \mathrm{Ba}$ & $0,49 \mathrm{Aa}$ & $1,12 \mathrm{Ba}$ & $3,41 \mathrm{Aa}$ \\
2.000 & $0,14 \mathrm{Ba}$ & $0,52 \mathrm{Aa}$ & $0,91 \mathrm{Ba}$ & $3,54 \mathrm{Aa}$ \\
\hline $\mathrm{CV}(\%)$ & \multicolumn{5}{c}{2,33} & 14,10 \\
\hline Obs.: médias seguidas pelas mesmas letras minúsculas nas colunas e
\end{tabular}
maiúsculas nas linhas não diferem entre si, pelo Teste de Tukey $(\mathrm{p}<0,05)$. 
TABELA 2 - Interação entre épocas do ano e doses de AIB para o número de raízes por estaca, comprimento de raízes (cm) e porcentagem de estacas com calo não-enraizadas da goiabeira 'Paluma'. Londrina-PR, 2005.

\begin{tabular}{|c|c|c|c|c|c|c|}
\hline \multirow{2}{*}{$\begin{array}{l}\text { Doses de AIB } \\
(\mathrm{mg} / \mathrm{L})\end{array}$} & \multicolumn{2}{|c|}{ Numero de raízes por estaca ${ }^{a}$} & \multicolumn{2}{|c|}{$\begin{array}{l}\text { Comprimento de raízes } \\
\qquad(\mathrm{cm})^{\mathrm{a}}\end{array}$} & \multicolumn{2}{|c|}{$\begin{array}{c}\text { Estacas com calo } \\
(\%)^{\mathrm{b}}\end{array}$} \\
\hline & Primavera & Verão & Primavera & Verão & Primavera & Verão \\
\hline 0 & $1,83 \mathrm{Aa}$ & $1,25 \mathrm{Ab}$ & $8,47 \mathrm{Aa}$ & $4,37 \mathrm{Bb}$ & $55,00 \mathrm{Aa}$ & $65,00 \mathrm{Aa}$ \\
\hline 500 & $1,84 \mathrm{Aa}$ & $2,0 \mathrm{Ab}$ & $8,16 \mathrm{Aa}$ & $7,87 \mathrm{Ab}$ & $56,25 \mathrm{Aa}$ & $57,50 \mathrm{Aab}$ \\
\hline 1.000 & $1,74 \mathrm{Aa}$ & $1,87 \mathrm{Ab}$ & 7,72 Aa & $7,50 \mathrm{Ab}$ & $46,25 \mathrm{Aab}$ & $36,25 \mathrm{Abc}$ \\
\hline 1.500 & $1,88 \mathrm{Ba}$ & $4,5 \mathrm{Aa}$ & $7,82 \mathrm{Ba}$ & $11,87 \mathrm{Aa}$ & $57,50 \mathrm{Aa}$ & $17,50 \mathrm{Bc}$ \\
\hline 2.000 & $1,59 \mathrm{Ba}$ & 4,0 Aa & $8,41 \mathrm{Ba}$ & $12,25 \mathrm{Aa}$ & $25,00 \mathrm{Ab}$ & $22,50 \mathrm{Ac}$ \\
\hline
\end{tabular}

Obs.: médias seguidas pelas mesmas letras minúsculas nas colunas e maiúsculas nas linhas não diferem entre si, pelo Teste de Tukey $(\mathrm{p}<0,05)$. ${ }^{\mathrm{a}}=$ dados transformados em $\sqrt{x} ;{ }^{\mathrm{b}}=$ dados transformados em arco-seno $\sqrt{x / 100}$.

TABELA 3 - Porcentagem de sobrevivência, porcentagem de estacas enraizadas e porcentagem de retenção foliar para a goiabeira 'Paluma'. Londrina-PR, 2005.

\begin{tabular}{lccc}
\hline Épocas & $\begin{array}{c}\text { Sobrevivência } \\
(\%)\end{array}$ & Estacas enraizadas (\%) & $\begin{array}{c}\text { Retenção foliar } \\
(\%)\end{array}$ \\
\hline Primavera & $88,5 \mathrm{a}$ & $53,75 \mathrm{a}$ & $86,75 \mathrm{a}$ \\
Verão & $88,0 \mathrm{a}$ & $52,25 \mathrm{a}$ & $88,00 \mathrm{a}$ \\
\hline Doses de AIB (mg/L) & & & \\
\hline 0 & $91,25 \mathrm{a}$ & $36,25 \mathrm{~d}$ & $88,75 \mathrm{a}$ \\
500 & $86,25 \mathrm{a}$ & $40,00 \mathrm{~cd}$ & $86,25 \mathrm{a}$ \\
1.000 & $88,75 \mathrm{a}$ & $55,62 \mathrm{bc}$ & $88,75 \mathrm{a}$ \\
1.500 & $85,00 \mathrm{a}$ & $59,37 \mathrm{ab}$ & $85,00 \mathrm{a}$ \\
2.000 & $90,00 \mathrm{a}$ & $73,75 \mathrm{a}$ & $88,12 \mathrm{a}$ \\
\hline CV (\%) & 15,58 & 32,28 & 18,57 \\
\hline
\end{tabular}

Obs.: médias seguidas pelas mesmas letras nas colunas não diferem entre si, pelo Teste de Tukey $(\mathrm{p}<0,05)$.

TABELA 4 - Porcentagem de sobrevivência, porcentagem de estacas enraizadas e massas seca e fresca de raízes por estaca (g) da goiabeira 'Paluma' enraizadas em diferentes substratos. Londrina-PR, 2005.

\begin{tabular}{lcccc}
\hline Substratos & $\begin{array}{c}\text { Sobrevivência } \\
(\%)\end{array}$ & $\begin{array}{c}\text { Estacas } \\
\text { enraizadas }(\%)\end{array}$ & $\begin{array}{c}\text { Massa seca } \\
(\mathrm{g})\end{array}$ & $\begin{array}{c}\text { Massa fresca } \\
(\mathrm{g})\end{array}$ \\
\hline $\mathrm{CAC}^{\mathrm{a}}$ & $87,25 \mathrm{a}$ & $54,0 \mathrm{a}$ & $0,22 \mathrm{a}$ & $1,48 \mathrm{a}$ \\
$\mathrm{VGM}^{\mathrm{b}}$ & $89,25 \mathrm{a}$ & $52,0 \mathrm{a}$ & $0,24 \mathrm{a}$ & $1,67 \mathrm{a}$ \\
\hline $\mathrm{CV}(\%)$ & 15,58 & 32,28 & 2,33 & 14,10 \\
\hline
\end{tabular}

Obs.: médias seguidas pelas mesmas letras nas colunas não diferem entre si, pelo Teste de Tukey $(\mathrm{p}<0,05) .{ }^{a}$ : CAC $=$ casca de arroz carbonizada; ${ }^{\text {b}}:$ VGM $=$ vermiculita.

Para a massa seca e fresca de raízes, as concentrações de 1.500 e $2.000 \mathrm{mg} / \mathrm{L}$ foram superiores quando as estacas foram coletadas no verão, sendo as médias 0,49 e $0,52 \mathrm{~g} ; 3,41$ e 3,54g, respectivamente (Tabela 1 ).

Para o número de raízes por estaca e comprimento de raízes, as doses de 1.500 e $2.000 \mathrm{mg} / \mathrm{L}$ foram superiores quando as estacas
TABELA 5 - Número de raízes por estaca, comprimento médio de raízes $(\mathrm{cm})$, porcentagem de retenção foliar e porcentagem de estacas com calo não-enraizadas da goiabeira 'Paluma' em diferentes substratos. Londrina-PR, 2005.

\begin{tabular}{|c|c|c|c|c|}
\hline Substratos & $\begin{array}{l}\text { Número de } \\
\text { raízes por } \\
\text { estaca }^{c}\end{array}$ & $\begin{array}{c}\text { Comprimento } \\
\text { de raízes } \\
(\mathrm{cm})^{\mathrm{c}}\end{array}$ & $\begin{array}{l}\text { Retenção } \\
\text { foliar (\%) }\end{array}$ & $\begin{array}{l}\text { Estacas com } \\
\text { calo }(\%)^{\mathrm{d}}\end{array}$ \\
\hline $\mathrm{CAC}^{\mathrm{a}}$ & $2,15 \mathrm{a}$ & $8,71 \mathrm{a}$ & $86,5 \mathrm{a}$ & $42,5 \mathrm{a}$ \\
\hline $\mathrm{VGM}^{\mathrm{b}}$ & $2,35 \mathrm{a}$ & $8,17 \mathrm{a}$ & $88,25 \mathrm{a}$ & $45,25 \mathrm{a}$ \\
\hline CV (\%) & 25,33 & 23,84 & 18,57 & 33,56 \\
\hline
\end{tabular}

Obs.: médias seguidas pelas mesmas letras nas colunas não diferem entre si pelo, Teste de Tukey $(\mathrm{p}<0,05)$. ${ }^{\text {a }}$ : $\mathrm{CAC}=$ casca de arroz carbonizada; ${ }^{\mathrm{b}}:$ VGM $=$ vermiculita. ${ }^{\mathrm{c}}=$ dados transformados em $\sqrt{x} ;{ }^{\mathrm{d}}=$ dados transforma-dos em arco-seno $\sqrt{x / 100}$.

TABELA 6 - Porcentagem de sobrevivência, porcentagem de estacas enraizadas e massa seca e fresca de raízes por estaca (g) da goiabeira 'Século XXI' em diferentes substratos. Londrina-PR, 2005.

\begin{tabular}{|c|c|c|c|c|}
\hline & Sobrevivência (\%) ${ }^{c}$ & Estacas enraizadas $(\%)^{\mathrm{C}}$ & Massa seca (g) & Massa fresca $(\mathrm{g})$ \\
\hline \multicolumn{5}{|l|}{ Épocas } \\
\hline Primavera & $66,25 \mathrm{~b}$ & $41,0 \mathrm{a}$ & $0,23 \mathrm{a}$ & $1,49 \mathrm{a}$ \\
\hline$\underline{\text { Verão }}$ & $79,75 \mathrm{a}$ & $41,5 \mathrm{a}$ & $0,20 \mathrm{a}$ & $1,28 \mathrm{a}$ \\
\hline \multicolumn{5}{|l|}{ Substratos } \\
\hline $\mathrm{CAC}^{\mathrm{a}}$ & $75,0 \mathrm{a}$ & $47,0 \mathrm{a}$ & $0,24 \mathrm{a}$ & $1,57 \mathrm{a}$ \\
\hline $\mathrm{VGM}^{\mathrm{b}}$ & $71,0 \mathrm{a}$ & $35,5 \mathrm{~b}$ & $0,19 \mathrm{a}$ & $1,20 \mathrm{a}$ \\
\hline \multicolumn{5}{|c|}{$\underline{\text { Doses de AIB (mg/L) }}$} \\
\hline 0 & $77,5 \mathrm{a}$ & $41,25 \mathrm{a}$ & $0,15 \mathrm{c}$ & $0,80 \mathrm{~b}$ \\
\hline 500 & $76,25 \mathrm{a}$ & 39,37 a & $0,18 b c$ & $1,13 \mathrm{~b}$ \\
\hline 1.000 & $70,62 \mathrm{a}$ & 43,75 a & $0,24 \mathrm{ab}$ & $1,59 \mathrm{~b}$ \\
\hline 1.500 & $70,62 \mathrm{a}$ & $41,25 \mathrm{a}$ & $0,22 a b c$ & $1,20 \mathrm{~b}$ \\
\hline$\underline{2.000}$ & $70,00 \mathrm{a}$ & $40,62 \mathrm{a}$ & $0,30 \mathrm{a}$ & $2,21 \mathrm{a}$ \\
\hline $\mathrm{CV}(\%)$ & 27,18 & 25,70 & 2,79 & 12,74 \\
\hline
\end{tabular}

Obs.: médias seguidas pelas mesmas letras nas colunas não diferem entre si, pelo Teste de Tukey $(\mathrm{p}<0,05)$. a: $\mathrm{CAC}=$ casca de arroz carbonizada; ${ }^{\mathrm{b}}: \mathrm{VGM}=$ vermiculita. $^{\mathrm{c}}=$ dados transformados em arco-seno 
TABELA 7 - Número médio de raízes por estaca, comprimento médio de raízes por estaca $(\mathrm{cm})$, porcentagem de retenção foliar e porcentagem de estacas com calo não-enraizadas da goiabeira 'Século XXI' em diferentes substratos. Londrina-PR 2005.

\begin{tabular}{|c|c|c|c|c|}
\hline & $\begin{array}{c}\text { Número de raízes por } \\
\text { Estaca }^{\circ}\end{array}$ & $\begin{array}{l}\text { Comprimento de raízes } \\
(\mathrm{cm})\end{array}$ & $\begin{array}{c}\text { Retenção Foliar } \\
(\%)^{\mathrm{d}}\end{array}$ & $\begin{array}{c}\text { Estacas com calo } \\
(\%)^{\mathrm{d}}\end{array}$ \\
\hline \multicolumn{5}{|l|}{ Épocas } \\
\hline Primavera & $1,54 \mathrm{~b}$ & $10,12 \mathrm{a}$ & $64,25 \mathrm{~b}$ & $63,75 \mathrm{a}$ \\
\hline Verão & $1,97 \mathrm{a}$ & $9,42 \mathrm{a}$ & $78,75 \mathrm{a}$ & $41,25 \mathrm{~b}$ \\
\hline \multicolumn{5}{|l|}{ Substratos } \\
\hline $\mathrm{CAC}^{\mathrm{a}}$ & $1,97 \mathrm{a}$ & $10,35 \mathrm{a}$ & $74,50 \mathrm{a}$ & $55,75 \mathrm{a}$ \\
\hline $\mathrm{VGM}^{\mathrm{b}}$ & $1,54 \mathrm{~b}$ & $9,19 \mathrm{~b}$ & $68,50 \mathrm{a}$ & $49,25 \mathrm{a}$ \\
\hline \multicolumn{5}{|c|}{ Doses de AIB (mg/L) } \\
\hline 0 & $1,63 \mathrm{~b}$ & $9,26 \mathrm{a}$ & $73,12 \mathrm{a}$ & $55,62 \mathrm{a}$ \\
\hline 500 & $1,43 \mathrm{~b}$ & 9,25 a & $76,25 \mathrm{a}$ & $56,87 \mathrm{a}$ \\
\hline 1.000 & $1,89 \mathrm{ab}$ & $9,72 \mathrm{a}$ & $70,00 \mathrm{a}$ & $48,12 \mathrm{a}$ \\
\hline 1.500 & $1,43 \mathrm{~b}$ & $10,01 \mathrm{a}$ & $78,75 \mathrm{a}$ & $52,50 \mathrm{a}$ \\
\hline 2.000 & $2,41 \mathrm{a}$ & $10,60 \mathrm{a}$ & $59,37 \mathrm{a}$ & $49,37 \mathrm{a}$ \\
\hline CV (\%) & 19,01 & 24,46 & 18,34 & 23,59 \\
\hline
\end{tabular}

Obs: médias seguidas pelas mesmas letras nas colunas não diferem entre si, pelo Teste de Tukey $(\mathrm{p}<0,05)$. ${ }^{\text {a }}$ : CAC $=$ casca de arroz carbonizada; b:VGM=vermiculita. ${ }^{\mathrm{c}}=$ dados transformados em $\sqrt{x} ;{ }^{\mathrm{d}}=$ dados transformados em arco-seno $\sqrt{x / 100}$

foram coletadas no verão, sendo as médias 4,5 e 4,0 raízes; 11,87 e $12,25 \mathrm{~cm}$, respectivamente (Tabela 2). Para a porcentagem de estacas com calo não-enraizadas, as menores doses de AIB e a estaquia realizada na primavera foram superiores em relação aos demais tratamentos (Tabela 2).

Com relação à taxa de sobrevivência das estacas, à porcentagem de estacas enraizadas e à retenção foliar, não foram observadas diferenças significativas entre as diferentes épocas do ano (Tabela 3). Para a porcentagem de estacas enraizadas, houve aumento significativo crescente com relação ao aumento das doses de AIB, sendo que, para a dose de $2.000 \mathrm{mg} / \mathrm{L}$, foram observadas $73,75 \%$ de estacas enraizadas (Tabela 3 ). Para as outras variáveis, não foram constatadas diferenças significativas.

Quanto aos substratos casca de arroz carbonizada (CAC) e vermiculita (VGM), não foram constatadas diferenças significativas para as variáveis estudadas (Tabelas 4 e 5).

\section{'Século XXI'}

Não foi constatada interação significativa entre os fatores época do ano, substrato e doses de AIB para a 'Século XXI'.

Entre as épocas do ano, foram observadas diferenças significativas (Tabelas 6 e 7) para a taxa de sobrevivência, o número de raízes por estaca e a retenção foliar, sendo as maiores médias observadas quando as estacas foram coletadas no verão, cujas médias foram 79,75 e 66,25\%; 1,97 e 1,54; 78,75 e 64,25\%, respectivamente. A porcentagem de estacas com calo nãoenraizadas diminuiu, sendo as médias de $63,75 \%$ na primavera e $41,25 \%$ no verão (Tabela 7 ).

Entre os diferentes substratos, houve superioridade da casca de arroz carbonizada em relação à vermiculita para porcentagem de estacas enraizadas, número de raízes por estaca e comprimento de raízes, cujas médias foram 47,0 e 35,5\%; 1,97 e 1,54 raíz; 10,35 e 9,19cm, respectivamente (Tabelas 6 e 7).

Com relação às doses de AIB, para a massa seca de raízes, as doses de 1.000; 1.500 e $2.000 \mathrm{mg} / \mathrm{L}$ resultaram em médias de 0,$24 ; 0,22$ e $0,30 \mathrm{~g}$, respectivamente. Para a massa fresca de raízes e para o número médio de raízes por estaca, a dose de $2.000 \mathrm{mg} / \mathrm{L}$ resultou nas maiores médias $(2,21 \mathrm{~g}$ e 2,41 raízes por estaca, respectivamente) (Tabelas 6 e 7).

\section{DISCUSSÃO}

Em função dos resultados obtidos, foi possível constatar que a época na qual é feita a estaquia das goiabeiras, é de fundamental importância na região norte do Paraná, pois essa tem influência direta no enraizamento e no desenvolvimento das estacas, o que está de acordo com as observações feitas por Klein et al. (2000). Os melhores resultados obtidos no verão são explicados uma vez que, para as condições locais, o inverno um pouco mais prolongado que as regiões tropicais, resulta em um início do crescimento ativo das goiabeiras somente a partir de setembro, onde, no verão, os ramos se encontram bem desenvolvidos e com material de reserva disponível, possibilitando melhor enraizamento das estacas.

Entretanto, em função da cultivar e da região, os resultados podem ser mais amplos. Tavares et al. (1995) e Dutra et al. (2002) verificaram bom enraizamento de estacas de goiabeira a partir da primavera até o verão, onde estes últimos autores determinaram baixos teores de triptofano nas estacas, o que pode ser explicado por este aminoácido ter sido convertido em ácido indolacético (AIA) e utilizado pelas plantas para o seu desenvolvimento.

Como as auxinas são reguladores vegetais que exercem importante função no crescimento e desenvolvimento vegetal e também estão relacionadas à estimulação do enraizamento adventício em estacas, quando usadas exogenamente (Mohr \& Schopfer, 1995; Hartmann \& Kester, 2002; Hopkins \& Hüner, 2004; Kerbauy et al., 2004), foi possível constatar o uso benéfico desse regular no enraizamento das estacas das cultivares estudadas, o que está de acordo com os resultados obtidos por outros autores (Pereira et al., 1983; Pereira et al., 1991; Kersten \& Ibañes, 1993; Bacarin et al., 1994; Tavares et al., 1995; Costa Jr. et al., 2003). A vantagem do uso do AIB na estaquia das estacas das goiabeiras, verificada neste trabalho, consistiu não somente em aumentar a porcentagem de estacas enraizadas, mas também em proporcionar a estas outras características desejadas, como maior massa do sistema radicial, comprimento e número de raízes emitidas, o que resulta, segundo Pereira et al. (1991), Bacarin et al. (1994) e Tavares et al. (1995), em melhor padronização do desenvolvimento das raízes e qualidade das mudas formadas. Esses fatores são fundamentais quando o objetivo é a produção de mudas em escala comercial, já que a sua qualidade tem grande influência na constituição dos pomares formados. Quando se obtêm mudas de qualidade, pode-se esperar o bom desempenho quanto ao desenvolvimento e à produção das plantas originadas quando todos os tratos culturais exigidos são aplicados.

A escolha dos substratos para o enraizamento das cultivares de goiabeira estudadas deve ser ponderada, uma vez que nenhum mostrou ser superior ao outro em relação às principais variáveis analisadas. As principais vantagens da casca de arroz carbonizada são o baixo custo e as qualidades físicas que este 
confere, como umidade, porosidade e drenagem adequadas. Além disso, pela fácil drenagem da água da nebulização intermitente, este substrato resulta em menor peso das bandejas, facilitando o seu manuseio no viveiro. Entretanto, para a produção de mudas em larga escala, pode haver dificuldade em se obter a palha de arroz em grandes quantidades e ainda há a necessidade de carbonizá-la antes de ser utilizada. Para a vermiculita, as principais vantagens são a facilidade de obtenção, uma vez que é um substrato comercial, além das características fitossanitárias e físicas, como boa retenção de umidade e porosidade que este material confere.

Além de escolher um substrato satisfatório para a estaquia da goiabeira, deve-se atentar para que ela ocorra no momento propício, após a poda e a formação dos ramos com qualidade. Com base nos resultados obtidos, recomenda-se que a obtenção e o preparo de estacas das cultivares Paluma e Século XXI, na região norte do Paraná, sejam realizados durante o verão, no mês de fevereiro.

\section{CONCLUSÕES}

1. A coleta de estacas herbáceas no meio do verão é mais indicada para a propagação das goiabeiras 'Paluma' e 'Século XXI' no norte do Paraná.

2. A casca de arroz carbonizada e a vermiculita são indicadas para o enraizamento de estacas de goiabeira 'Paluma'.

3. As doses de 1.500 e $2.000 \mathrm{mg} / \mathrm{L}$ de AIB são as mais apropriadas para promover as melhores características do enraizamento de estacas herbáceas das cvs. Paluma e Século XXI, respectivamente.

\section{REFERÊNCIAS}

ANDRADE, R.A.; MARTINS, A.B.G. Propagação vegetativa de porta-enxertos para citros. Revista Brasileira de Fruticultura, Jaboticabal, v.25, n.1, p.134-136, 2003.

BACARIN, M.A.; BENINCASA, M.M.P.; ANDRADE, V.M.M.; PEREIRA, F.M. Enraizamento de estacas aéreas de goiabeira (Psidium guajava L.): efeito do ácido indolilbutírico (AIB) sobre a iniciação radicular. Científica, São Paulo, v. 22, n.1, p. 71-79, 1994.

COSTA JR, W.H.; SCARPARE FILHO, J.A.; BASTOS, D.C. Estiolamento da planta-matriz e uso de ácido indolbutírico noenraizamento de estacas de goiabeiras. Revista Brasileira de Fruticultura, Jaboticabal, v.25, n2, p.301-304, 2003.

CYRILLO, F.L.L., KIMURA, A.; ROBERTO, S.R.; TEIXEIRA, L.A.J.; PEREIRA, F.M. Multiplicação de porta-enxertos de videira por meio de estacas semilenhosas, em dois substratos, conduzidos em câmara de nebulização. Revista Brasileira de Fruticultura, Jaboticabal, v. 21, n. 3, p. 266-268, 1999.

DUTRA, L.F.; KERSTEN, E.; FACHINELLO, J.C. Época de coleta, ácido indolbutírico e triptofano no enraizamento de estacas de pessegueiro. Scientia Agricola, Piracicaba, v.59, n.2, p.327$333,2002$.
FERREIRA, D. F. Análises estatísticas por meio do Sisvar para Windows versão 4.0. In: REUNIÃO ANUAL DA REGIÃO BRASILEIRA DA SOCIEDADE INTERNACIONAL DE BIOMETRIA, 45., 2000, São Carlos. Anais... São Carlos: UFSCAR. p. 255-258.

FRANGI, P.; NICOLA, S. Study of propagation by cutting of five species native to south África. Acta Horticulturae, Wageningen, v.683, p.313-318, 2005.

GOMES, J. E.; PERECIN, D.; MARTINS, A.B.G.; IGNACIO, N. Enraizamento de estacas herbáceas de genótipos de acerola em câmara de nebulização intermitente tratadas com ácido indol butírico em duas épocas. Revista Brasileira de Fruticultura, Jaboticabal, v.22, n. 3, p. 407-412, 2000.

HARTMANN, H.T.; KESTER, D.E. Plant propagation: principles and practices. $7^{\text {th }}$ ed. New Jersey: Englewood Cliffs, 2002. 880p.

HOPKINS, W.G; HÜNER, N.P.A. Introduction to plant physiology. $3^{\text {rd }}$ ed. Hoboken: John Wiley \& Sons, 2004. 560p.

KÄMPF, A.N.; COSTA, G.J.C. da; SCHNEIDER, P.S.; VIELMO, H.A.; SILVA, L. da; CRUZ, F.Z.; BASTOS, R.M.; HESSE, H.H.; PARADEDA, M.R.H.M. Produção comercial de plantas ornamentais. Guaíba: Agropecuária, 2000. 254p.

KERBAUY, G.B.; FERREIRA, A.G.; VAZ, A.P.A.; FURLANI, A.M.C.; FETT-NETO, A.G.; LIMA, D.U.; CHU, E.P.; SERAPHIN-STACCIARINI, E.; MERCIER, H.; SANTOS, H.P.; PIMENTA, J.P.; SODEK, L.; CORDEIRO, L.; PERES, L.E.P.; ZAIDAN, L.B.P.; FERNANDES, M.S.; TINÉ, M.A.; BUCKERIDGE, M.S.; MINHOTO, M.J.; GUERRA, M.P.; MAJEROWICZ, N.; FIGUEIREDO-RIBEIRO, R.C.L.; COLLI, S.; SOUZA, S.R.; CARDOSO, V.J.M.; ALMEIDA, V.P. Fisiologia vegetal. São Paulo: Guanabara-Koogan, 2004. 452p.

KERSTEN, E.; IBAÑEZ, U.A. Efeito do ácido indolbutírico no enraizamento de estacas de ramos de goiabeira (Psidium guajava L.) em condição de nebulização e teor de aminoácidos totais. Revista Brasileira de Fruticultura, Cruz das Almas, v.15, n.1, p.87-89, 1993.

KLEIN, J.D.; COHEN, S.; HEBBE, Y. Seasonal variation in rooting ability of myrtle (Myrtus communis L.) cuttings. Scientia Horticulturae, Amsterdan, v.83, n.1, p. 71-76, 2000.

KRISANTINI, S.; JOHNSTON, M.; WILLIAMS, R.R.; BEVERIDGE, C. Adventitious root formation in Grevillea (Proteaceae), an Australian native species. Scientia Horticulturae, Amsterdan, v.107, n.2, p.171$175,2006$.

MANICA, I.; ICUMA, I. M.; JUNQUEIRA, N. T. V.; SALVADOR, J. O.; MOREIRA, A.; MALAVOLTA, E. Fruticultura tropical 6: goiaba. Porto Alegre: Cinco Continentes, 2000. 374 p.

MAYER, N.A.; PEREIRA, F.M.; NACHTIGAL, J.C. Propagação do umezeiro (Prunus mume Sieb \& Zucc.) por estaquia herbácea. Revista Brasileira de Fruticultura, Jaboticabal, v.23, n.3, p.673-676, 2001. 
MELETTI, L.M.M.; TEIXEIRA, L.A.J.; COELHO, S.M.B.M.; SACRAMENTO, B.M.M.; FOLTRAN, D.E.; SOARES, N.B. Propagação de frutíferas tropicais. Guaíba: Agropecuária, 2000. 239p.

MOHR, H.; SCHOPFER, P. Plant physiology. Berlin: Springer Heidelberg, 1995.629p.

OLIVEIRA, A.P.; NIENOW, A.A.; CALVETE, E.O. Capacidade de enraizamento de estacas semilenhosas e de cultivares de pessegueiro tratadas com AIB. Revista Brasileira de Fruticultura, Jaboticabal, v.25, n.2, p.282-285, 2003.

PEREIRA, F.M.; CARVALHO, C.; NACHTIGAL, J.C. Século XXI: nova cultivar de goiabeira de dupla finalidade. Revista Brasileira de Fruticultura, Jaboticabal, v.25, n.3, p.498-500, 2003.

PEREIRA, F.M.; PETRECHEN, E.H.; BENINCASA, M.M.P.; BANZATTO, D.A. Efeito do ácido indolbutírico no enraizamento de estacas herbáceas de goiabeira (Psidium guajava L.) das cultivares 'Rica' e 'Paluma', em câmaras de nebulização. Científica, São Paulo, v. 19, n. 2, p. 199 -206, 1991.

PEREIRA, F.M. Rica e Paluma: novas cultivares de goiabeira. In: CONGRESSO BRASILEIRO DE FRUTICULTURA, 7., 1984, Florianópolis. Anais... Florianópolis: SBF, 1984. p.524-528.

PEREIRA, F.M.; OIOLI, A.A.P.; BANZATTO, D.A. Enraizamento de diferentes tipos de estacas enfolhadas de goiabeira (Psidium guajava L.) em câmara de nebulização. Científica, São Paulo, v.11, n.2, p.239-244, 1983.

ROM, R.C.; CARLSON, R.F. Rootstocks for fruit crops. Canada: John Wiley \& Sons, 1987. 494p.

TAVARES, M.S.W.; KERSTEN, E.; SIEWERDT, F. Efeitos do ácido indolbutírico e da época de coleta no enraizamento de estacas de goiabeira (Psidium guajava L.). Scientia Agricola, Piracicaba, v.52, n.2, p.310-317, 1995. 